\title{
O uso do vlog no desenvolvimento da habilidade oral em língua inglesa
}

\author{
Rafaela de Souza Alves \\ Universidade de Taubaté \\ Vanessa Dantas Carvalho \\ Universidade de Taubaté
}

\begin{abstract}
Resumo
O presente trabalho trata de apresentar o gênero $v \log$ e as possibilidades que o gênero oferece no auxílio ao processo de ensino-aprendizagem de língua inglesa com foco na habilidade oral de estudantes do ensino fundamental. Esta pesquisa objetiva-se produzir uma sequência didática, sugerindo o trabalho com o gênero $v \log$, possibilitando a prática da língua oral vinculada a algo prazeroso ao estudante.

Palavras-chave: língua inglesa, habilidade oral, vlog, sequência didática.
\end{abstract}

\begin{abstract}
This article deals with the genre vlog and the possibilities that the genre offers as assistance in the process of English teaching-learning with a focus on the oral ability of elementary school students. This research aims to produce a didactic sequence, with suggestions for work with the vlog genre that enables students to have oral language practice linked to something pleasurable to them.
\end{abstract}

Keywords: English language, oral skills, vlog, didactic sequence.

\section{INTRODUÇÃO}

A partir do estudo do $v \log$ e das possibilidades que esse gênero oferece no auxílio ao processo de ensino-aprendizagem de língua inglesa com foco no desenvolvimento da compreensão e produção oral de estudantes do segundo ciclo do ensino fundamental, esta pesquisa teve como objetivo produzir uma sequência didática com o referido gênero. $\mathrm{O}$ trabalho com a oralidade em sala de aula tem sido desafiador devido a vários fatores. Um deles é concretizá-lo de forma significativa, mobilizando os três tipos de conhecimento citados nos Parâmetros Curriculares Nacionais de Língua Estrangeira: conhecimento sistêmico, conhecimento de mundo e conhecimento da organização dos textos. "Esses conhecimentos compõem a competência comunicativa do aluno e o preparam para o engajamento discursivo." (BRASIL, 1998, p. 29)

Concomitantemente, estamos vivendo um contexto histórico de avanços tecnológicos, principalmente em relação à informação e comunicação. A criação das redes sem fio e dos dispositivos móveis como notebooks, tablets, smartphones 
facilitaram o acesso livre à internet. Esse acesso tem direcionado algumas mudanças nas práticas sociais. "Surgem novas formas de ser, de se comportar, de discursar, de se relacionar, de se informar, de aprender" como citam Rojo e Barbosa (2015, p. 116). Essa nova geração da internet "muda o fluxo de comunicação e, em tese, acaba com a cisão produtores/leitores, possibilitando que todos publiquem na rede e exerçam simultaneamente os dois papéis(...)" (p. 119).

Em meio a todo esse contexto, está o estudante que não apenas consome o conteúdo disponível na rede, como também produz, tece comentários, expõe pontos de vista, entre outras diversas atividades comunicativas. E qual seria o papel da escola? "Nesse movimento contemporâneo que se constitui em torno das redes digitais, as instituições de ensino, em todos os níveis, não deveriam ficar à margem, atuando apenas como consumidoras de informações" (BONILLA; PRETTO, 2015, p. 151).

Para Rojo e Barbosa as demandas sociais devem ser abordadas pelos currículos escolares. Sendo assim, a escola deve:

\footnotetext{
"(...) propiciar experiências significativas com produções de diferentes culturas e com práticas, procedimentos e gêneros que circulam em ambientes digitais: refletir sobre participações, avaliar a sustentação das opiniões, a pertinência e adequação de comentários, a imagem que se passa, a confiabilidade das fontes, apurar os critérios de curadoria e de seleção de textos/produções, refinar os processos de produção e recepção de textos multissemióticos" (p. 135).
}

Com o avanço da tecnologia e a acessibilidade à internet a sociedade se transforma e com ela os discursos. Novos tipos de texto nascem das necessidades discursivas. Hoje por exemplo, fazem parte das opções de entretenimento dos estudantes os vídeos do Youtube e entre esses vídeos, temos o vlog. Os vloggers aqueles que produzem $v \log s$ - são os novos ídolos dos adolescentes. Assistir aos $v \log s$ e acompanhar as produções diárias ou semanais de um vlogger são ações comuns para muitos estudantes (alguns já estão até mesmo produzindo seus próprios vlogs). Portanto, é reconhecida neste trabalho a importância em compreender um pouco mais sobre esse tipo de texto e o conteúdo discursivo apresentado por esses vloggers. Por fazer parte do dia-a-dia do adolescente, o vlog poderia ser utilizado como material de estudo pelo professor de língua inglesa, tanto para trazer reflexões sobre o que está sendo consumido, quanto para incentivar o estudo do idioma no aspecto da compreensão e produção oral.

Espera-se que a sequência didática aqui apresentada possa contribuir para que o professor de língua inglesa ofereça ao estudante uma possibilidade de desenvolver a 
habilidade oral de forma significativa. A sequência didática traz também momentos que proporcionarão reflexões acerca do que os estudantes estão consumindo e produzindo nos ambientes digitais.

Para tanto, utilizaram-se como fundamento os estudos sobre desenvolvimento da habilidade oral de Oliveira (2015), as discussões sobre gênero textuais e tecnologia de Marcuschi (2004) e Braga (2013), as investigações sobre multiletramentos de Rojo e Almeida (2012), Rojo e Barbosa (2015), as pesquisas sobre o gênero vlog de Lima e Luna (2012), e a proposta de sequência didática de Dolz e Schneuwly (2004).

Os procedimentos metodológicos seguiram a seguinte dinâmica: 1) pesquisas bibliográficas dos autores anteriormente citados; 2) elaboração de uma sequência didática visando o desenvolvimento da linguagem oral no ensino da língua inglesa por meio do gênero $v \log$.

\section{FUNDAMENTAÇÃO TEÓRICA}

Nesta seção serão abordadas a concepção de gêneros discursivos, bem como as características do vlog, os multiletramentos, os fundamentos teóricos sobre a habilidade oral em língua estrangeira e os procedimentos para a elaboração de uma sequência didática.

\section{Gêneros, vlog e multiletramentos}

Os gêneros discursivos fazem parte da nossa vida diária e organizam a nossa comunicação. Segundo Rojo e Barbosa (2015), os gêneros apresentam:

\footnotetext{
"diferentes modos de vida e circunstâncias ligados às diversas esferas/campos de comunicação, por sua vez relacionadas com os vários tipos de atividade humana e determinadas, em última instância, pela organização econômica da sociedade, gerariam tipos temáticos, composicionais e estilísticos de enunciados/textos relativamente estáveis" (p. 64).
}

Para ilustrar esse conceito, vejamos o exemplo dado pelas autoras: na esfera íntima, o valor "amor" leva os namorados a utilizarem uma linguagem pessoal, delicada com o outro. Já na esfera publicitária, o valor "convencimento" leva o publicitário a elaborar textos em uma linguagem sugestiva, para mover o leitor à ação de consumir. E acrescentam: "diferentes participantes de diferentes esferas de atividade desempenham diferentes papéis que os levam a atividades diversas que resultam em textos diversos" (p. 76). 
O vlog é um gênero que nasce do avanço das tecnologias digitais, mas que, sobretudo, é fruto da necessidade discursiva de uma nova geração movida por determinados valores. Porém, Braga cita a leitura e produção de textos como desafios do professor. "Em meios digitais, estamos todos imersos em enunciados multissemióticos e hipertextuais" (2013, p. 41). E acrescenta: "linguagens que antes dependiam de diferentes suportes para registro e acesso de informação passaram a ser armazenadas todas juntas na memória de um único meio" (p. 43).

O gênero $v \log$, por exemplo, situa-se nesse contexto. Embora seu conteúdo seja apresentado em forma de vídeo, o gênero se constitui de diversos tipos de linguagens e links. Piero (2012, p. 2), ao investigar as definições para o gênero, cita que o vlog "é um tipo particular de blog apresentado em forma de vídeo ou um conteúdo audiovisual" em que o autor "expõe suas ideias sobre algum tema e permite a interatividade com outros usuários (...)". Piero cita o entretenimento como a função predominante do gênero através dos textos narrativos e argumentativos; porém podendo apresentar outros fins em medidas menores, com textos explicativos e descritivos. No geral estrutura-se com a apresentação do tema, desenvolvimento e encerramento dentro de um planejamento prévio, um texto pré-escrito. Embora um gênero oral, o vlog constitui um exemplo de "escrito falado" pelo seu "alto nível de planejamento" (PIERO, 2012, p. 7).

O conteúdo do vlog é variado, mas observa-se uma tendência a apresentar temas polêmicos e cotidianos, pontos de vista e o humor, como é observado por Lima e Luna (2012). A essas observações, acrescenta-se a elaboração de roteiro do que será apresentado, parentetizações e digressões inseridas propositalmente, caráter de espontaneidade e abertura para feedbacks.

O sucesso do vlog, assim como os demais gêneros emergentes no contexto da tecnologia digital, pode estar relacionado ao fato de "reunir num só meio várias formas de expressão, tais como, texto, som e imagem" e à "rapidez da veiculação e sua flexibilidade linguística (...)." (MARCUSCHI, 2004, p. 13 e 14).

Rojo e Barbosa (2015) definem um texto multissemiótico ou multimodal como aquele que recorre a mais de uma modalidade de linguagem em sua composição. Na mídia digital, diferentemente da mídia impressa, podemo-nos dispor de "todas as modalidades e semioses - língua oral e escrita (verbal), linguagem corporal (gestualidade, danças, performances, vestimentas), áudio (música e outros sons não verbais) e imagens estáticas e em movimento(...)" (2015, p. 111 e 112). 
Sendo assim, o grande desafio do professor não está nas características dos novos textos, mas nas práticas escolares de leitura/escrita que já eram restritas e insuficientes mesmo na era do texto impresso, como afirma Lemke ${ }^{1}$ (2010 apud ROJO, 2012).

Braga (2013, p. 46) também coloca que:

"(...) 'letrar' o aluno certamente pressupõe ir muito além das letras e das práticas tradicionais de letramento. Esquemas interpretativos para as diferentes informações imagéticas,(...) tornam-se salientes demais para serem desconsiderados.

Rojo (2012) acrescenta que a escola em busca desse alfabetismo deve ater-se nas possibilidades práticas para que os alunos se transformem em criadores de sentido. "Para que isso seja possível, é necessário que eles sejam analistas críticos, capazes de transformar os discursos e significações, seja na recepção ou na produção." (p. 29)

\section{Habilidade oral em língua estrangeira}

O desenvolvimento da habilidade oral é um aspecto importante no processo de ensino-aprendizagem de língua estrangeira, tendo em vista que um dos objetivos de quem aprende uma segunda língua é conseguir falar e entender o que os outros estão dizendo. Essa competência oral é constituída pela compreensão e produção oral, que devem ser exploradas em sala de aula a fim de contribuir para a competência comunicativa dos alunos, no caso deste estudo, em língua inglesa.

Devido à negligência histórica em relação ao desenvolvimento da habilidade oral em sala de aula de línguas no ensino regular, percebe-se, ainda hoje, que os professores dão pouca atenção a essa habilidade. Isto ainda pode ser justificado com outros fatores, como aponta o PCN (BRASIL, 1998, p.21)

Deve-se considerar também o fato de que as condições na sala de aula da maioria das escolas brasileiras (carga horária reduzida, classes superlotadas, pouco domínio das habilidades orais por parte da maioria dos professores, material didático reduzido a giz e livro didático etc.) podem inviabilizar o ensino das quatro habilidades comunicativas. Assim, o foco na leitura pode ser justificado pela função social das línguas estrangeiras no país e também pelos objetivos realizáveis tendo em vista as condições existentes.

Ainda que os PCN possuam argumentos para a negligência com a habilidade oral, o avanço da tecnologia e da internet mudaram o cenário da Educação nos dias de

\footnotetext{
${ }^{1}$ LEMKE, J. Letramento Metamidiático: transformando significados e mídias. Trabalhos em Linguística Aplicada. Campinas; jul-dez 2010, p. 455-479.
} 
hoje. Agora os professores possuem ferramentas que não tinham dez anos atrás, o que pode facilitar o trabalho com a habilidade oral em sala de aula (FABRÍCIO, 2015).

Neste estudo argumenta-se que o vlog pode ser uma dessas ferramentas. É pertinente então, discutir como desenvolver a habilidade oral (compreensão e produção oral) na sala de aula.

Oliveira (2015) argumenta que as atividades de pré-compreensão oral, cuja finalidade é ativar os conhecimentos prévios dos alunos, são importantes para construir sentidos acerca de um texto, devido ao fato de a compreensão depender de tais conhecimentos. Dessa maneira, as atividades de pré-compreensão têm a finalidade de ativar esses conhecimentos. Segundo o autor, essa fase de ativação do conhecimento prévio é importante, pois os alunos

“... precisam ser preparados para realizar atividades de compreensão oral. Se
não houver uma preparação, eles provavelmente encontrarão dificuldades
para realizá-las e, pior, sentirão um baque na sua autoestima, o que pode se
tornar uma barreira psicológica para o aprendizado.”. (OLIVEIRA, 2015, p.
78)

As atividades de pré-compreensão são realizadas antes das atividades de compreensão oral e tem a finalidade de estabelecer o contexto (personagens ou pessoas, local), de motivar os alunos (dependendo do tema) e de ativar ou construir esquemas mentais dos alunos. É importante salientar que não há duração para as atividades de précompreensão. Oliveira (2015), aponta algumas sugestões de atividades:

- Brainstorming - o professor diz o tema e pede por ideias, palavras, expressões relacionadas a ele. Essa atividade pode ser feita no quadro, por meio de um mapa semântico.

- O professor diz ou escreve no quadro expressões, palavras que fazem parte do texto falado que se espera que o aluno saiba, a fim de conseguir compreender bem o texto.

- Os alunos leem o que o enunciado do exercício pede, e tentem prever as respostas, fazendo com que se concentrem nas informações relacionadas aos exercícios.

Após as atividades de pré-compreensão oral, tem-se as atividades de compreensão oral, na qual podem ser trabalhadas micro-habilidades como busca de informações específicas, reconhecimento de palavras, busca por ideias gerais e realização de inferências.

Conforme Oliveira (2015), na micro-habilidade de busca por informações específicas, os alunos realizam o processo de decodificação, no qual procuram por palavras-chave que os guiarão no momento de ouvir o texto. Um exemplo de atividade 
com esse objetivo é quando os alunos precisam buscar informações para preencher quadros, mapas ou lacunas.

Para a prática da habilidade 'reconhecimento de palavras', o aluno pode preencher os espaços em branco com alguma palavra, como nas atividades de música. Essa atividade pode ter formas diferentes, podendo se tirar palavras com um critério discursivo (pronomes, conjunções, substantivos) ou dando opções de possíveis respostas (OLIVEIRA, 2015).

Os alunos precisam ser capazes de ouvir um texto, mesmo não compreendendo detalhes, mas conseguir dizer do que ele trata, trabalhando-se assim a busca por ideias gerais. Perguntas que podem ajudar nessa compreensão podem ser sobre os falantes, onde eles estão e sobre o que eles estão falando.

Com relação a micro-habilidade de realizar inferências, pode-se dizer que ela possibilita o "ouvinte fazer deduções do que não está dito no texto, do que está nas entrelinhas, do contexto de produção, dos indivíduos, dos elementos não linguísticos" (OLIVEIRA, 2015, p.91).

Foram citadas acima algumas atividades para o trabalho com a compreensão oral. Passa-se agora para atividades relacionadas com a produção oral dos alunos, que segundo Oliveira (2015), envolve o aprimoramento da pronúncia bem como o desenvolvimento de conhecimentos linguísticos enciclopédicos e textuais e microhabilidades de precisão gramatical e fluência.

Ao abordar a produção oral dos alunos, o professor deve ter em mente que alguns aspectos psicológicos podem influenciar, como a timidez e o medo de errar dos alunos, o que provoca ansiedade e insegurança. Como então lidar com todos esses aspectos e tentar trabalhar a oralidade dos alunos? É preciso que o professor converse com seus alunos, da importância do erro para a aprendizagem, de se arriscar, e também forneça informações bem claras do que se espera que os alunos façam. Outra maneira é trabalhar em duplas, o que facilita ao aluno arriscar mais.

Na produção oral também é importante realizar atividades de pré-fala, como estabelecer o contexto, ativar ou construir esquemas mentais e diagnosticar a familiaridade dos alunos com o tópico da atividade (OLIVEIRA, 2015).

Com relação às micro-habilidades de fala, uma delas é a produção inteligível dos sons, ou seja, o trabalho com a pronúncia dos alunos. O professor deve abordar erros comuns de pronúncia que os brasileiros fazem e deixar os alunos conscientes desses erros. O uso apropriado dos elementos gramaticais e do vocabulário também é 
importante, pois os alunos precisam ter um vocabulário amplo e saber usar as palavras adequadamente. Cabe aqui dizer que a repetição é necessária para o desenvolvimento da fala, porém, o professor deve procurar fazer com que essas repetições sejam significativas aos alunos.

Segundo Oliveira (2015), os alunos precisam ter em mente qual registro eles utilizarão em determinada situação de comunicação: um registro formal ou informal. É importante também que os alunos tenham estratégias de comunicação como negociação de sentidos, (compreender o que foi dito, por meio de repetições), circunlocução (uso de várias palavras para descrever algo), neologismo (criação de palavras) e uso de linguagem não-verbal (gestos).

As considerações acerca de como trabalhar a compreensão e produção oral, bem como as atividades em sala de aula podem auxiliar o trabalho do professor ao abordar essa habilidade com os alunos, e serviram para nortear a elaboração das atividades práticas desta pesquisa.

\section{Sequência Didática}

Neste estudo pretende-se utilizar o vlog para desenvolver a habilidade oral dos alunos. Considerando então o vlog como um gênero discursivo, decidiu-se trabalhar com sequências didáticas. Segundo Dolz e Schneuwly (2004, p.83) uma sequência didática é "um conjunto de atividades escolares organizadas, de maneira sistemática, em torno de um gênero textual ou escrito". As sequências didáticas possuem a finalidade de auxiliar o aluno no domínio de um gênero discursivo, podendo assim, escrever ou falar mais adequadamente em determinada situação de comunicação.

As sequências didáticas são estruturadas da seguinte maneira:

Figura 1 - Esquema de uma sequência didática

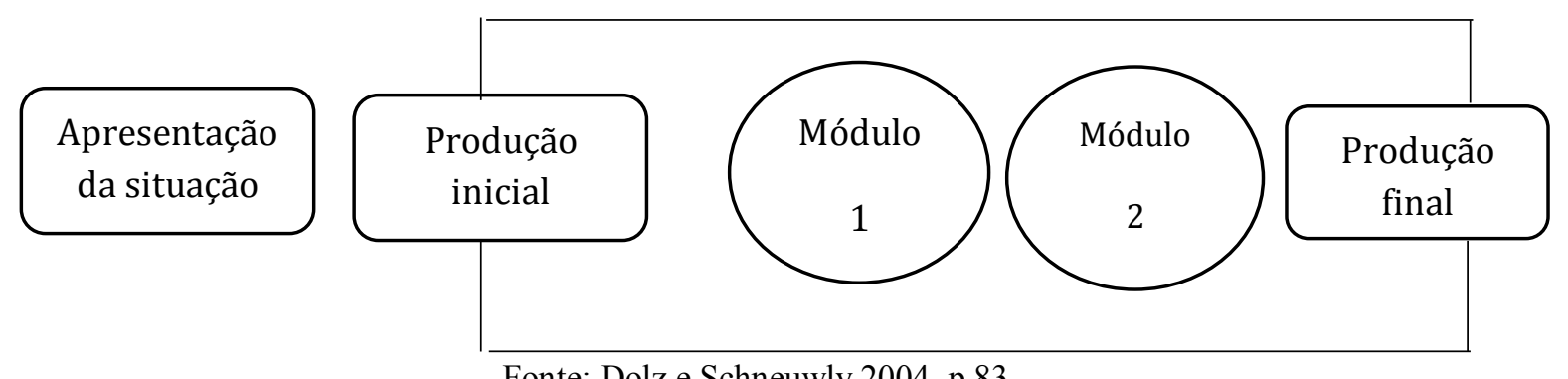

Fonte: Dolz e Schneuwly 2004, p.83 
$\mathrm{Na}$ apresentação da situação, os alunos constroem uma representação da situação de comunicação que irão realizar na produção final. Eles devem compreender bem o que irão fazer, qual o "problema" a ser resolvido. Algumas questões auxiliam nessa etapa: qual o gênero do texto? A quem se dirige a produção? Que forma assumirá a produção? Quem participará da produção? Nessa etapa é importante também saber quais conteúdos serão trabalhados e qual será o tema abordado. (DOLZ e SCHNEUWLY, 2004).

A produção inicial diz respeito ao primeiro texto oral ou escrito que os alunos irão elaborar. Conforme Dolz e Schneuwly (2004), é de se esperar que o aluno não será capaz de reproduzir o gênero com todas as características que ele possui, irá fazê-lo parcialmente, o que mostrará ao professor as capacidades que o aluno já possui e as que precisa alcançar. A produção inicial motiva tanto o aluno quanto o restante da sequência, assim, ela não necessita ser uma produção completa, somente a final será, tornando-se reguladora da sequência didática. Na produção inicial, os alunos irão realizar um texto oral ou escrito concretizando os elementos abordados na apresentação inicial. O professor utilizará essa produção inicial para refinar, modular e adaptar a sequência da melhor maneira para aprimorar as capacidades dos alunos.

Nos módulos serão trabalhados os problemas que aparecerão na primeira produção dos alunos, fornecendo-lhes instrumentos para superar essas dificuldades. Então, nos módulos são vistas as capacidades que os alunos precisam ter para dominar cada vez mais o gênero escolhido. Para Dolz e Schneuwly (2004), as atividades nos módulos devem ser alternadas. As atividades e exercícios precisam ser variados, relacionando habilidades de leitura, produção escrita e oral. Exemplos de atividades podem ser a análise de textos orais ou escritos, a produção de textos e a elaboração de uma linguagem comum para falar dos textos. Durante essas atividades, os alunos vão construindo conhecimento acerca do gênero, como características, vocabulário, linguagem discursiva e linguagem técnica. É interessante que durante esse processo, os alunos criem listas que resumam tudo o que foi adquirido nos módulos.

$\mathrm{Na}$ produção final os alunos colocam em práticas as noções e instrumentos que elaboraram durante os módulos. A produção final mostra ao aluno o que ele conseguiu aprender, quais conhecimentos ele construiu durante o processo. E ao professor serve de avaliação somativa.

Um aspecto pertinente ao elaborar uma sequência didática é a duração. Não há indicação de tempo para cada atividade, pois a proposta requer que a sequência se 
adeque aos conhecimentos que o aluno já tem e às capacidades que ele precisa adquirir. Sendo assim, torna-se inviável pensar na duração de cada parte da sequência didática.

\section{RESULTADOS}

O resultado desta pesquisa é a sequência didática elaborada com base no gênero discursivo $v \log$, abordando a habilidade oral em língua inglesa.

\section{SEQUÊNCIA DIDÁTICA DO GÊNERO VLOG}

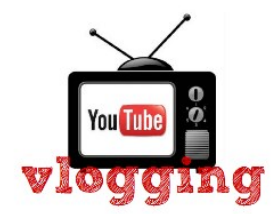

Essa sequência didática tem por objetivo desenvolver a habilidade oral, tanto na compreensão quando produção. No começo há um vlog em português, a fím de que os alunos sejam contextualizados acerca do gênero escolhido. Depois, são apresentados três $v \operatorname{logs}$ em inglês, os quais se destinam à prática da compreensão oral. Em seguida, há os módulos em que se propõe trabalhar a produção dos alunos passo a passo.

Além de se trabalhar com a habilidade oral, é possível também trabalhar a habilidade escrita, por meio da interpretação dos exercícios, bem como a resposta às perguntas.

A sequência didática foi elabora tendo em mente alunos do final do segundo ciclo do ensino fundamental, ou seja, alunos de $8^{\circ}$ e $9^{\circ}$ ano. Porém, nada impede que ela também seja aplicada a alunos do ensino médio.

\section{APRESENTAÇÃO INICIAL}

\section{- Primeiro momento: Contextualização de vlog}

Objetivo: Identificar os hábitos de Internet que os alunos têm, bem como seus gostos e finalidades, contextualizar o aluno sobre vlogs, levantar o conhecimento prévio que os alunos têm sobre o gênero discursivo em questão.

Procedimento: Fazer perguntas acerca do cotidiano dos alunos. (Respostas pessoais)

- What are your favorite websites?

- What do you use them for?

- Do you use Youtube?

- What kind of videos are there on Youtube?

- Do you watch vlogs?

- What do you understand by vlog?

- Who are your favorite vloggers? 
- Has anyone ever produced a vlog?

\section{-Segundo momento: Características e funções do vlog}

Objetivo: Ativar conhecimentos prévios dos alunos sobre o gênero $v \log$, ter contato com o gênero e levantar informações sobre características e funções do $v l o g$ depois de assistir a um.

\section{Procedimento:}

1. Fazer as seguintes perguntas com relação ao gênero vlog:

- What is a vlog used for?

- What do people do in a vlog?

- What is there in a vlog?

- What are the kinds of vlogs?

- What channels do you know on Youtube?

- Have you ever heard about the channel nomegusta?

2. Alunos assistem ao vlog abaixo, enquanto anotam as características, objetivos, tipo e efeitos presentes no vídeo. O vlog apresenta o tema de rótulos, e expressa a opinião do vlogger que nós não devemos nos deixar influenciar pelo que as outras pessoas pensam a nosso respeito. Temos que fazer o que gostamos independente do que os outros irão falar. O vlogger utiliza alguns exemplos para argumentar sua opinião, como chorar ao assistir filme, escolha por usar saia quadriculada, entre outros.

Figura 1 - Vlog 1

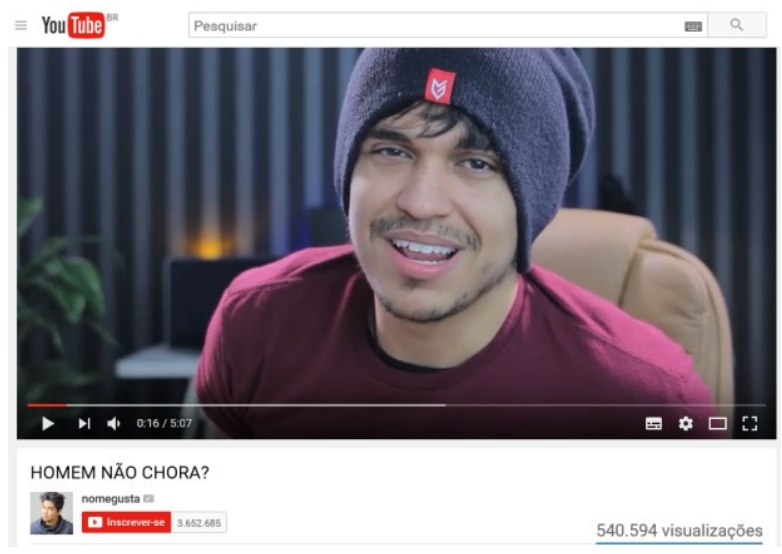

Fonte: https://www.youtube.com/watch?v=B-BXb4exvKw

3. Em duplas, os alunos discutem as informações que escreveram sobre o vlog assistido.

Respostas variadas: vlogger expressa sua opinião, é engraçado, dá exemplos, fala rápido, ilustra com cenas diferentes, retrata o cotidiano, faz propaganda do canal no final, efeitos de edição. 
4. Duplas compartilham com a sala o que discutiram.

5. Os alunos discutem sobre o conteúdo do vídeo, o tema abordado: se concordam ou não com a opinião do vlogger.

6. Mencionar aos alunos a proposta de eles produzirem um vlog no final da sequência didática. O público alvo será uma turma de alunos de outra cidade que, por sua vez, também produzirá um vlog. As produções dos alunos estarão disponíveis em um blog, com o objetivo de fazer a interação entre os alunos.

\section{- Terceiro momento: Compreendendo vlogs em Inglês (1)}

Objetivo: estudar o gênero $v \log$, praticar a compreensão oral em inglês, trabalhar a précompreensão oral e as micro-habilidades de reconhecimento de palavras e busca por ideias gerais.

O vlog trata das razões do vlogger odiar ir ao dentista. Ele ilustra com performances algumas dessas razões, como a música de ópera ao fundo, a tentativa do dentista de manter uma conversa com o paciente, entre outras.

\section{Procedimento:}

1. Atividade de pré-compreensão oral: O professor faz as seguintes perguntas:

(Respostas pessoais; dependendo do nível do aluno, elas podem ser respondidas em inglês.)

a. How often do you go to the dentist?

b. Do you like going to the dentist? Why?

c. Why is going to the dentist a traumatic experience for some people?

2. Atividade de pré-compreensão oral: o professor escreve as seguintes palavras no quadro e verifica se os alunos conhecem os significados:

music - swallow - granny - strange - hate - fingers - bite - dreaded - freak out - scraping - smile - magazines

3. Atividade de compreensão oral: os alunos irão assistir pela primeira vez ao vlog abaixo e colocar as palavras da atividade anterior na ordem em que aparecem no vídeo.

1. freak out 2 . strange 3 . hate 4 . granny 5 . magazines 6 . dreaded 7. smile 8 . fingers 9 . swallow 10 . bite 11. music 12. scraping 


\section{Figura $2-V \log 2$}

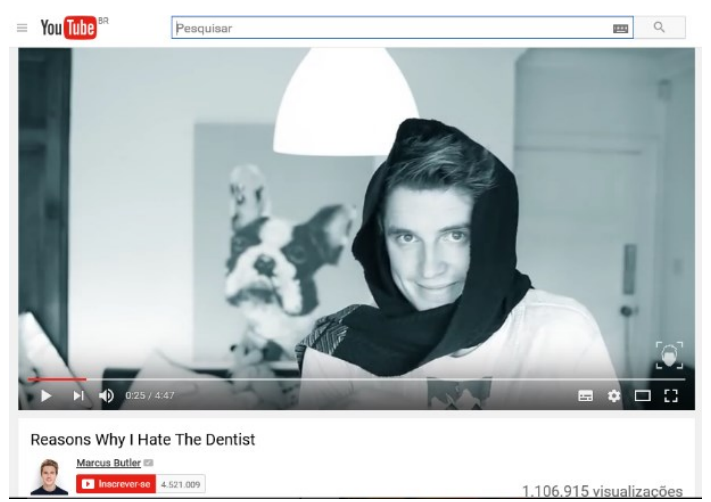

Fonte: https://www.youtube.com/watch?v=b63vHcD8mC8

4. Atividade de compreensão oral: os alunos irão assistir o vlog novamente e escrever com suas palavras, em inglês, o que entenderam sobre as razões que o vlogger deu para odiar o dentista.

Reason 1: It seems you walked into a Friday afternoon granny social event.

Reason 2: The magazines are five years old, the Lego for kids.

Reason 3: Dreaded name call.

Reason 4: Massive loving warming smile

Reason 5: The dentist tries to make a conversation with his fingers in the person's mouth.

Reason 6: The dentist talks about figures and numbers that you don't understand.

Reason 7: You get the urge to swallow, and end up biting the dentist's fingers.

Reason 8: The dentist has loud opera music.

Reason 9: Bits of metals scraping inside your teeth.

Reason 10: The vacuum device.

5. Os alunos respondem às seguintes perguntas: (podem ser respondidas em inglês, se os alunos conseguirem).

a. What are the characteristics of this vlog?

b. Are there any differences from the vlog we watched in Portuguese?

c. In relation to the language used in the vlog, what do you have to say?

(Chamar a atenção dos alunos para algumas questões linguísticas do vlog como o uso de cumprimentos no começo do vídeo - hello-, as perguntas que o vlogger faz durante o 
vídeo, uso de gestos, mímicas, sons, palavras sequências como firstly e o uso de adjetivos).

d. Do you agree with the vlogger? Why?

e. Compare the vlogger's experience with Brazilians' experiences at the dentist.

Respostas variadas: o vlogger expressa sua opinião, conta de sua experiência, usa gestos, mímicas, é engraçado, faz propagando do canal.

\section{- Quarto momento: Compreendendo vlogs em Inglês (2)}

Objetivos: estudar o gênero $v \log$, praticar a compreensão oral em inglês, trabalhar a pré-compreensão oral e as micro-habilidades de reconhecimento de palavras e busca por informações gerais e específicas.

O vlog tem como tema 'amigos tóxicos', que são aqueles amigos que não fazem bem para uma pessoa. A vlogger apresenta cinco tipos de amigos tóxicos e faz uma performance de cada um deles (copião, negativo, interesseiro, fora da lei e o dramático).

\section{Procedimento:}

1. Atividade de pré-compreensão oral: Perguntar aos alunos o que eles entendem por "toxic friends" e pedir exemplos.

2. Atividade de compreensão oral. Quantos tipos de amigos Anna apresenta no vlog? O que Anna faz na parte final do vlog?

Five friends: she talks about her sponsor and shows the product.

\section{Figura $3-V \log 3$}

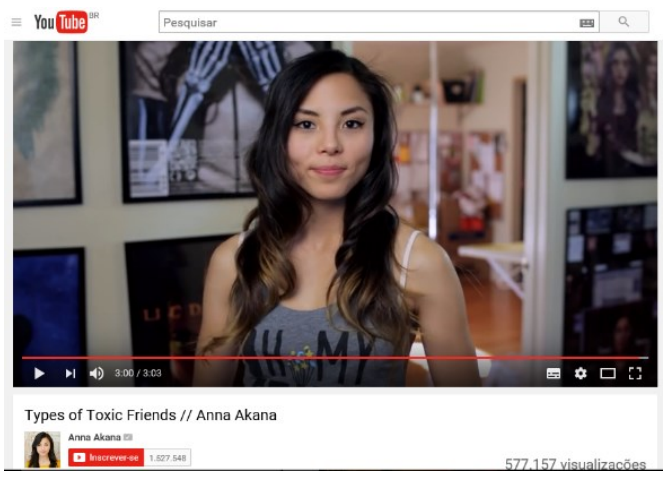

Fonte: https://www.youtube.com/watch?v=h2T-oUJzFYI

3. Atividade de compreensão oral. Os alunos assistem mais uma vez e escrevem o nome de cada amigo tóxico e o que eles entenderam sobre esses amigos.

1. Copycat ; 2. Negative Nancy; 3. Wild child; 4. Social climber; 5. Drama queen.

4. Atividade de compreensão oral. Os alunos escrevem as palavras que faltam. (01:45 01:58) 
If you have a toxic friend in your life, and talking things out just isn't gonna work, then break it off, pull the plug, nothing healthy is gonna come from that relationship. Do it right now.

5. Os alunos responderão às perguntas:

a. What are the characteristic of this vlog?

b. In relation to the language used in the vlog, what do you have to say?

c. Do you have or have you ever been a toxic friend?

Respostas variadas: A vlogger expõe sua opinião, dá exemplos, é engraçada, dramatiza, dá conselhos, faz propagando de seu patrocinador.

\section{- Quinto momento: Compreendendo vlogs em Inglês (3)}

Objetivos: estudar o gênero vlog, praticar a compreensão oral em inglês, trabalhar a pré-compreensão oral e as micro-habilidades de reconhecimento de palavras e busca por ideias gerais.

No vlog, há duas personagens (atuadas pela mesma pessoa), que respondem a algumas perguntas que os internautas escreveram.

\section{Procedimento:}

1. Atividade de pré-compreensão oral. Fazer as seguintes perguntas:

a. What is a Q \& A vlog? Have you ever watched one?

b. What is the function of a $v \log$ like that?

c. What kind of questions do you think are asked?

2. Atividade de pré-compreensão oral. Perguntar aos alunos o que eles conseguem entender de cada pergunta.

(2) If you could be an animal, what would you be? I would be a lion and you would be a worm.

(5) Will you follow me? No/Sure

(9) What has been your best moment of 2015 so far? Co-hosting with you/ I found an old band-aid yesterday.

(1) What is your opinion on dogs? I love dogs, they're so cute. / I love hot dogs.

(7) Can you name a word for every letter of the alphabet? Apple/Banana/Cat/Banana.

(4) Do you ever think about how different your life would be without Miranda Sings? You wouldn't have a good life, you wouldn't exist/ I think it's the other way around.

(8) When you get married, will you take Joshua's last name or keep your own? He's actually going to get my name./ That question was for me.

(3) What is your favorite lunch meat? Turkey meat/I eat all meat.

(10) If the whole world was listening, what is one thing you would say? Choose happiness, don't dwell on negativity, life is short, so be nice to people and enjoy yourself. / Subscribe to me.

(6) Are you going to get a cat since you don't live in an apartment anymore? They disagree in that one. 
3. Colocar em ordem as perguntas do exercício anterior de acordo com o que os alunos assistiram no $v \log$.

Figura $4-V \log 4$

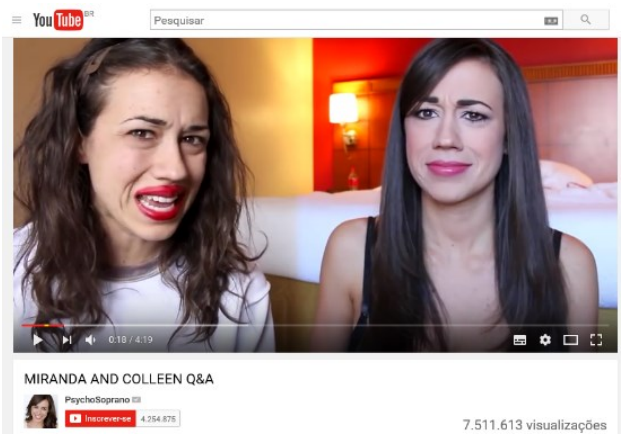

Fonte: https://www.youtube.com/watch?v=0MNAtPaGu6g

4. Atividade de compreensão oral. O que as vloggers responderam em cada pergunta?

5. Atividade de compreensão oral. Como é a personalidade de cada uma? Por que Miranda discute com Colleen?

Collen é simpática, alegre, já Miranda é depressiva, brava.

Elas discutem por Miranda não entender a brincadeira e por querer o noivo da outra.

6. Quais são as características do vlog?

Respostas variadas: As vloggers expõem suas opiniões sobre diversos tópicos, há perguntas que guiam o vlog, é engraçado, há diálogo e muitas reações faciais.

\section{PRODUÇÃO INICAL}

Depois de assistir a todos os vlogs e fazer um levantamento das características e funções de cada um deles, os alunos irão pensar em algum tema para produzirem um $v \log$.

Objetivo: aplicar todo o conhecimento que já construíram em relação ao gênero $v \log$.

\section{Procedimento:}

1. Brainstorming. Os alunos levantarão possíveis temas, assuntos que podem ser abordados em um vlog.

2. Os alunos podem trabalhar em duplas ou individualmente. Devem escolher o tema que gostariam de apresentar no $v$ log. 
3. Os alunos assistirão ao seguinte $v \log$ e anotarão as dicas para elaborar um roteiro de um $v \log$. O $v \log$ está em português, pois o objetivo é que os alunos vejam algumas dicas para a produção dos vlogs.

Figura 5 - Vlog 5

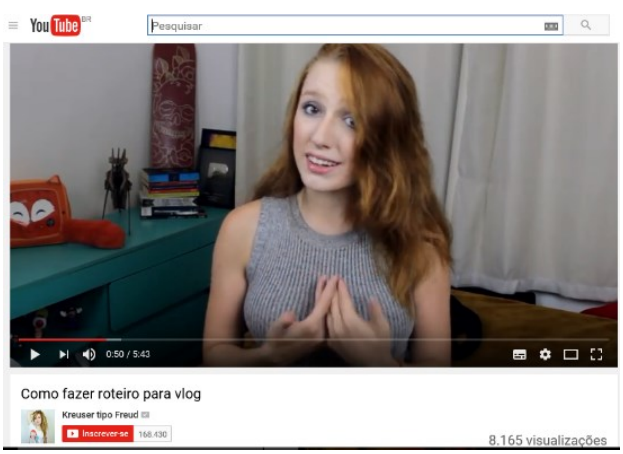

Fonte: https:/www.youtube.com/watch?v=FdbjUjfk78w

4. Os alunos pesquisarão na Internet sobre o assunto escolhido.

5. Alunos escrevem o roteiro para o $v \log$, podendo ser em português, mas com palavras que já sabem em Inglês.

- No roteiro os alunos podem escrever tudo o que querem falar no vlog, os efeitos que querem colocar, as possíveis dramatizações, entre outros.

\section{MÓDULOS}

Cabe aqui lembrar que os módulos são flexíveis e adaptáveis, pois eles dependem da produção inicial dos alunos, das dificuldades que apresentarem, das capacidades que ainda não têm. Sendo assim, os módulos devem ser montados de acordo com as necessidades dos alunos. Como essa é somente uma proposta de aplicação, serão dadas apenas algumas sugestões de módulos.

Nos módulos, os alunos irão refinar a produção inicial, reescrevê-la, colocar as palavras em Inglês, estruturar o roteiro para o $v \log$, praticar a pronúncia e a produção oral.

Módulo 1 - Estrutura do vlog

Neste módulo, os alunos irão pensar na estrutura do vlog. O professor deve sempre perguntar aos alunos o que eles já sabem, o que eles acham que deve vir na estrutura e construir juntos o conhecimento sobre a estrutura do $v \log$.

Possíveis tópicos a se pensar

- Cumprimentos, exposição do tema, apresentação de algum colaborador no vlog, introdução, argumentos, exemplos e conclusão do tema. Se quiserem, podem mencionar 
a propaganda de parcerias ou do próprio canal que eles quiserem criar. (Incentivar a criatividade)

\section{Módulo 2 - Expressando opiniões}

No segundo módulo os alunos irão pensar em como expressar suas opiniões, elaborar seus argumentos.

Possíveis tópicos

- Ser claro, preciso, objetivo, importância dos exemplos, dramatizações, gestos, efeitos de vídeo que podem ajudar, conjunções,

\section{Módulo 3 - Senso de humor}

O humor está presente em muitos vlogs. Assim, os alunos devem pensar em como produzir o humor, o que faz as pessoas rirem e como deixar o vlog engraçado.

Possíveis tópicos

- Exemplos de fatos rotineiros, relacionar pessoas famosas, rir de si mesmo, objetos diferentes, cenário, figurino, sotaque, personalidade, ironia, entonação, brincadeiras, eufemismo, caretas, piadas, rir dos defeitos, exagero, elemento surpresa, contar experiências, entre outros.

\section{Módulo 4 - Vocabulário e expressões}

É muito importante que os alunos façam uma boa escolha de vocabulário a ser utilizado no vlog. Ainda mais que estarão produzindo um vlog em língua inglesa, eles precisam ampliar suas escolhas, pesquisar palavras que querem colocar.

Possíveis tópicos

- Cumprimentos - Gírias/palavrões - Advérbios de sequência - Adjetivos de opinião.

\section{Módulo 5 - Produção oral}

Neste módulo, serão trabalhadas questões de pronúncia, questões gramaticais abordadas nos textos e fluência dos alunos.

Possíveis tópicos

- Dificuldades de pronúncia que os brasileiros têm, entonação, ordem das perguntas, presente simples, passado.

Observações

- É importante que o professor acompanhe de perto os textos que os alunos estão criando, e perceba se eles estão utilizando adequadamente a gramática e vocabulário nos textos. 


\section{Módulo 6-Ensaios}

É importante também que os alunos trabalhem os gestos, as expressões faciais, forma de se expressarem, personalidade que querem passar; montem os cenários.

Módulo 7 - Edição de vídeos

O aplicativo que será utilizado para gravar e editar os vídeos é o Kine master. Ele pode ser baixado no celular, o que torna o processo mais fácil tanto para os alunos quanto para o professor.

\section{PRODUÇÃO FINAL}

Depois de "refinarem" as produções iniciais durante os módulos, os alunos irão gravar os vlogs.

Observações importantes

- Duração mínima do vlog: 3 minutos.

- Nessa sequência didática os alunos irão trocar os vídeos com alunos de outra cidade. Os vídeos serão postados em um blog criado pelas professoras, no qual, futuramente, os alunos também farão comentários acerca dos $v \log s$ dos colegas.

\section{CONSIDERAÇÕES FINAIS}

Na tentativa de aproximar o estudante à habilidade oral no aprendizado da língua inglesa, observou-se no gênero vlog uma possibilidade que resultou na elaboração de uma sequência didática. Essa sequência sugere o trabalho com o vlog nas aulas de língua inglesa, sendo este, por sua vez, um gênero muito utilizado no entretenimento dos estudantes nos dias de hoje.

A pesquisa fundamentou-se nas concepções do desenvolvimento da habilidade oral, gêneros textuais no contexto tecnológico, multiletramentos e no ensino por meio de uma sequência didática para que o professor possa desenvolver um trabalho que atenda aos desafios desta atual sociedade, possibilitando momentos de reflexão acerca do que é produzido e consumido pelos alunos.

\section{REFERÊNCIAS}

BONILLA, M. H. S.; PRETTO, N. L. As tecnologias digitais: construindo uma escola ativista. In: BRAGA, D. B. (Org.). Tecnologias digitais da informação e comunicação e participação social: possibilidades e contradições. São Paulo: Cortez, 2015. 
BRAGA, D. B. Ambientes Digitais: reflexões teóricas e práticas. São Paulo: Cortex, 2013.

BRASIL, Ministério da Educação. Parâmetros curriculares nacionais terceiro e quarto ciclos do ensino fundamental. Língua estrangeira, Brasília, 1998.

DOLZ, J.; SCHNEUWLY, B. Sequências didáticas para o oral e a escrita: apresentação de um procedimento. In: SCHNEUWLY, B. E DOLZ, J. et al Gêneros orais e escritos na escola. Campinas: Mercado de Letras, 2004.

FABRÍCIO, R.B. Análise do potencial de um site com foco em desenvolvimento da habilidade oral em língua inglesa. 100 f. Monografia (Especialização em Práticas reflexivas e ensino-aprendizagem de inglês na escola pública). Pontifica Universidade Católica de São Paulo - São Paulo. 2015.

LIMA, F.; LUNA, R. P. Pensando o vlog como gênero textual aplicado ao ensino. In: III Simpósio Nacional de Linguagens e Gêneros Textuais - III SINALGE, 2012, Campina Grande. Linguagens, gêneros e discursos. João Pessoa: Ideia, 2012. v. 1. p. 638-649.

MARCUSCHI, L. A. Gêneros textuais emergentes no contexto da tecnologia digital. In:

MARCUSCHI, L. A.; XAVIER, A. C. (Orgs.) Hipertexto gêneros digitais. Rio de Janeiro: Editora Lucerna, 2004.

OLIVEIRA, L. M. Aula de inglês: do planejamento à avaliação. São Paulo: Parábola Editorial, 2015.

PIERO, J. L. de. El vlog como género discursivo: algunos aportes para su definición.

Jornaleras Revista científica de estudios literarios y linguisticos. v. 1, n. 1. 2012.

Disponível em:

$<$ http://www.fhycs.unju.edu.ar/Archivos/userupload/jornaleros/De_Piero_EL_VLOG_C OMO_GENERO_DISCURSIVO.pdf > Acesso em: 28 ago. 2016.

ROJO, R. Pedagogia dos multiletramentos: diversidade cultural e de linguagens na escola. In: ROJO, R.; MOURA, E. (Orgs.). Multiletramentos na escola. São Paulo: Parábola Editorial, 2012.

ROJO, R.; BARBOSA, J. P. Hipermodernidade, multiletramentos e gêneros discursivos. São Paulo: Parábola Editorial, 2015.

\section{AS AUTORAS}

Rafaela de Souza Alves é graduada em Letras (licenciatura em português e inglês e suas respectivas literaturas) pela FEPI (2014), possui especialização em metodologia do ensino da língua inglesa (2015) e está cursando metrado em Linguística Aplicada na Unitau. Atua como professora de inglês em escola pública e escola de idiomas em Delfim Moreira.

E-mail: rafa.alves_dm@hotmail.com

Vanessa Dantas Carvalho cursa o primeiro ano do Mestrado em Linguística Aplicada na Unitau. Possui graduação em Letras pela UMC (2005), Pedagogia pela FECGS 
(2012), pós graduação Lato Sensu em Docência da Língua Inglesa (2013) e Linguística (2014). Já lecionou em escolas de idiomas, escola bilíngue, curso técnico e hoje atua como professora de língua inglesa no segundo ciclo do Ensino Fundamental na Prefeitura Municipal de São José dos Campos.

E-mail: vanessa.dantas.carvalho@gmail.com 